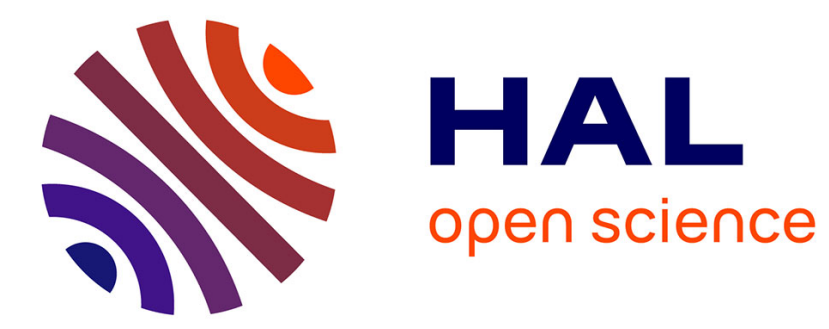

\title{
X-RAY LASER RESEARCH AT PALAISEAU
}

\author{
P. Jaeglé, G. Jamelot, A. Carillon, A. Klisnick
}

\section{To cite this version:}

P. Jaeglé, G. Jamelot, A. Carillon, A. Klisnick. X-RAY LASER RESEARCH AT PALAISEAU. Journal de Physique Colloques, 1986, 47 (C6), pp.C6-31-C6-40. 10.1051/jphyscol:1986604 . jpa00225847

\section{HAL Id: jpa-00225847 https://hal.science/jpa-00225847}

Submitted on 1 Jan 1986

HAL is a multi-disciplinary open access archive for the deposit and dissemination of scientific research documents, whether they are published or not. The documents may come from teaching and research institutions in France or abroad, or from public or private research centers.
L'archive ouverte pluridisciplinaire HAL, est destinée au dépôt et à la diffusion de documents scientifiques de niveau recherche, publiés ou non, émanant des établissements d'enseignement et de recherche français ou étrangers, des laboratoires publics ou privés. 
JOURNAL DE PHYSIQUE,

Colloque C6, supplément au $\mathrm{n}^{\circ} 10$, Tome 47, octobre 1986

\title{
X-RAY IASER RESEARCH AT PALAISEAU
}

P. JAEGLÉ, G. JAMELOT, A. CARILLON and A. KLISNICK

GRECO, "Interaction Laser-Matière", Ecole Polytechnique, F-91128 Palaiseau Cedex, France and Laboratoire de Spectroscopie Atomique et Ionique, Université Paris-Sud, F-91405 Orsay Cedex, France

\begin{abstract}
We present the soft $X$-ray laser experiments performed at Greco "Interaction Laser-Matière" (Palaiseau). They are mainly concerned with Lithium-like ions of aluminum in plasmas produced by $1.06 \mu \mathrm{Nd}-1$ aser. We describe the experimental set-up which performs time-dependent gain measurements. We report results showing a gain-length product of $2-2.5$ for the 3d - 5f line at $105.7 \mathrm{~A}$. Comparison is made between experiment and computational model. The possible limiting role of radiation trapping for long plasma column is discussed. We present the future projects regarding larger gains and new wavelengths.
\end{abstract}

\section{I - INTRODUCTION}

The X-ray laser research at Palaiseau includes experimental and theoretical studies of amplification by lithium-like ions in laser-produced plasmas /1,2/ and an investigation of gain feasability by resonant photoexcitation of neon-like strontium /3/. This paper is mainly devoted to the experimental gain measurements obtained with 1ithium-1ike aluminum and to the interpretation of the results in terms of plasma recombination effect. The program of research for the next future will be also shortly described. Detailed results on plasma modelling as well as theoretical predictions for other ions of the lithium sequency are to be found in separate papers presented at the same conference $/ 4,5 /$.

For a general understanding of the phenomena leading to population inversions in these plasmas we show, in fig. 1 , the diagram of Al $10^{+}-$ion energy levels and, in fig. 2, an example of time-dependent level population calculation during the plasma expansion. The most interesting feature of Li-like electronic structure for producing population inversions is the exceptionally fast radiative decay of $3 \mathrm{~d}_{5} 3 / 2$ to $2 \mathrm{p}_{3 / 2}$, levels, due to the large overlapping of the corresponding nodeless' radial Wavefunctions. Hence, the $3 d$ levels will easily curn out to be the lower levels of lasing transitions when the high-lying level populations are growing large owing to radiativo-collisional cascades occuring in the course of plasma recombination/6/. This is the result exemplified in fig. 2 for the 5f and $3 \mathrm{~d} 1$ levels. The arrow points the instant of the top of the laser pulse, whose the half-maximum duration, for this calculation, is of 2 ns. We see the predicted inversion to arise more than 4 ns later, that is well after the end of laser-energy deposition onto the metal target. The figure shows also the magnitude of plasma temperature and density at the time of population inversion. The drop of the curves reveals that inversion production is closely related to the cooling of expanding plasma.

\section{II - TIME-DEPENDENT SOFT X-RAY GAIN MEASUREMENTS}

Time-integrated absorption measurements, performed in the underdense region $\left(N_{e}<10^{21} \mathrm{~cm}\right)$ of laser-plasmas produced in a variety of conditions, have shown the 


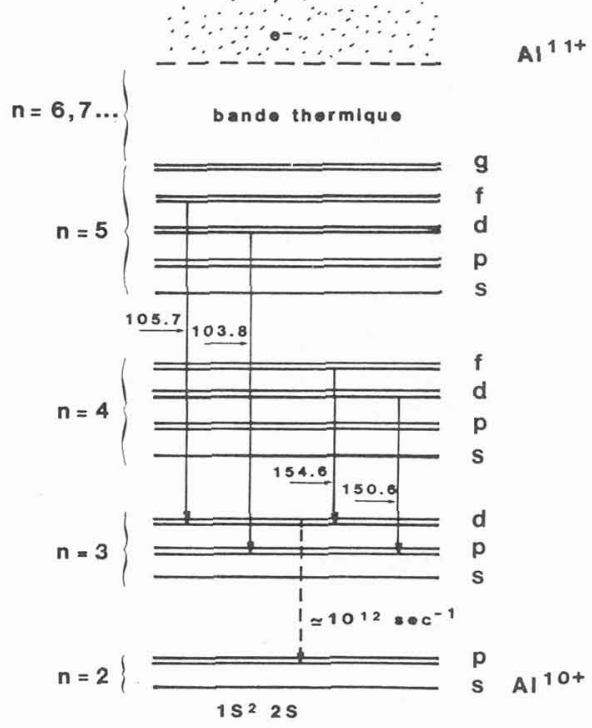

Fig. 1 - Level diagram of Li-like ions. The high quantum number level populations ( $n=6,7$ in the $f_{i g}$ ) are assumed to be in Boltzman's equilibrium with the He-like ground level. The $3 \mathrm{~d}$ levels decay very fast, so making possible population inversions to occur with some upper levels.

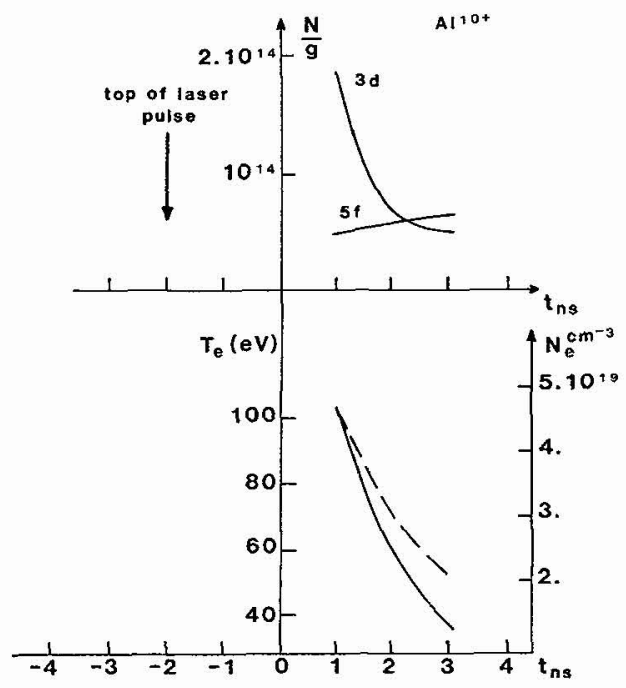

Fig. 2 - Example of calculated level population in recombining aluminum plasma. laser-pulse duration: 2 ns. Above, fig. 2 shows the begining of a $3 \mathrm{~d}-5 \mathrm{f}$ inversion taking place 4 ns after the top of the laser pulse; below, the solid curve represents the temperature drop at the same time; the dashed curve is the electronic density. 
3d-5f line of Al 10+ at 105.7 A to supply a negative share to the continuous absorption background $/ 1,7,8 \%$. Here we concentrate the attention on time-dependent measurements which are much more significant having regard to the true gain value as to the cheking of the plasma recombination scheme.

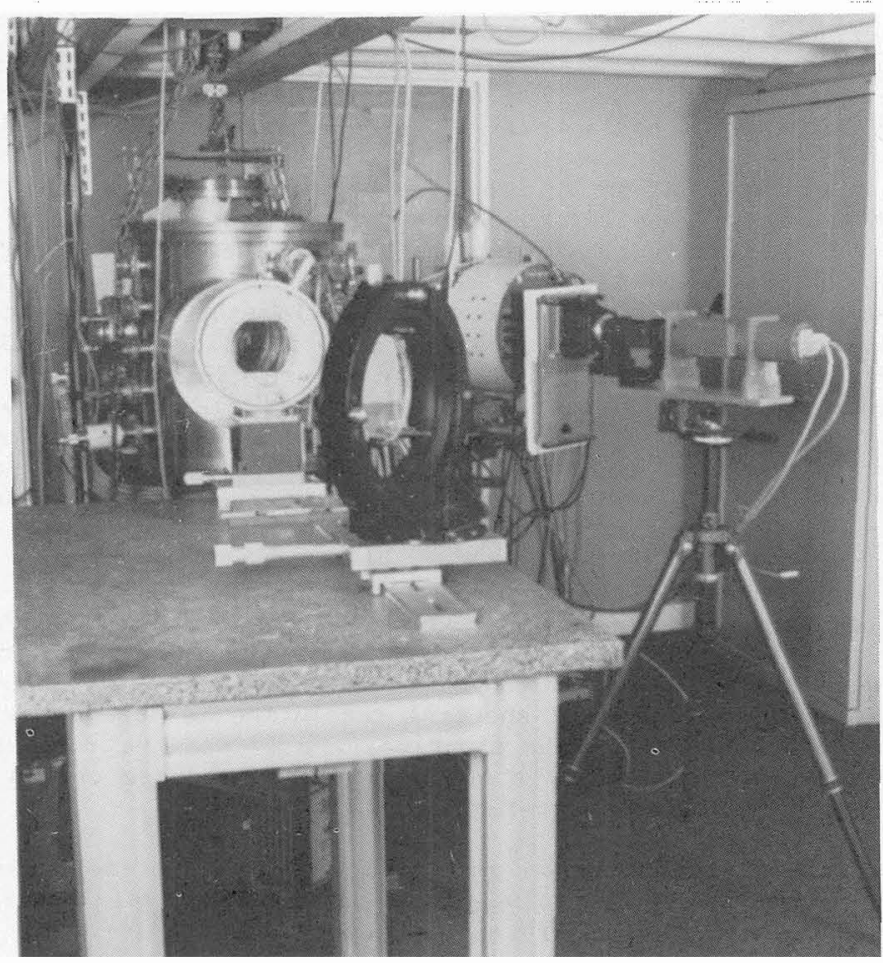

Fig. 3: View of the experimental set up showing the target chamber, the holder of the cylindrical focusing lens and the streak-camera connected to an optical Multichannel Analyser.

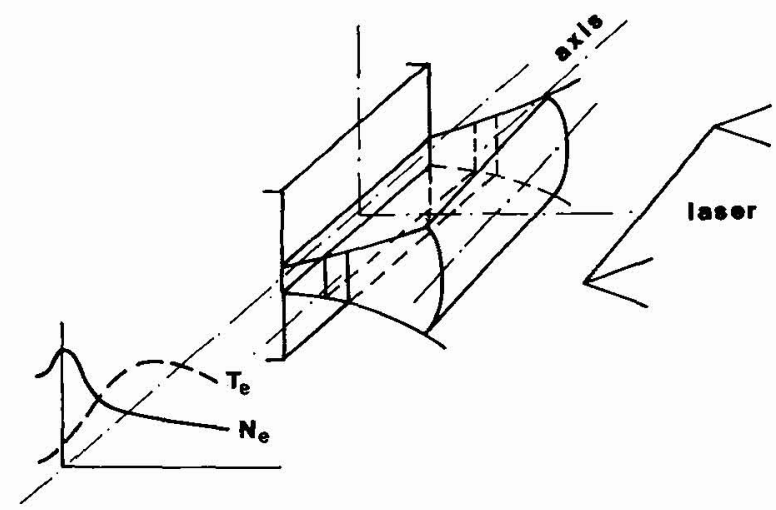

Fig. 4: This sketch presents some of the general features of a plasma column produced by a cylindrical focusing of laser-beam. The behaviour of electron density and temperature, perpendiculary to the target surface, is represented on the left side. If the illumnation is constant along the focal 1ine, the plasma is homogeneous in the axial direction which is used for gain measurements. 
Fig. 3 is a photography of the experimental device showing mainly the target chamber and the soft $X$-ray detection system. The laser itself cannot be seen on the picture. The deflection mirror, in the foreground, covers up the section of the 3600 grooves/mm grazing incidence grating. A rectangular diaphragm limiting the cross section of the laser beam, usually set near the entrance window has been removed in order to clear the sight of the cylindrical lens holder. When being in place, the diaphram improves the homogeneity of the line focal illumination on the target surface. It is also used for changing the line focal length at constant illumination by varying the horizontal size of the incoming beam.

Focusing the laser beam along a line is obtained in combining spherical and cylindrical lenses. Target and lenses can move together or separately under computer control in order to observe various sections of the plasma at we11-defined distances from the target and in fixed lighting conditions. The sketch of fig. 4 represents the plasma comumn produced close by the target surface by laser impact. The general features of electron density and temperature distributions, perpendiculary to the target, are displayed on the left side of the figure. Shifting the distance of the observed plasma section with respect to the target is clearly a way of changing the values of plasma parameters. The spatial resolution system, including a slit and a toroidal mirror, which makes possible to seal off a plasma section parallel to the target has been described elsewhere/9/. The axis of the observed plasma section is put on the same line as the soft $X$-ray spectrograph axis.

In the right part of the photography of fig. 3 one can see the streak-camera connected with an Optical Multichannel Analyser. This set up provides digital data from the time-dependent spectrum emitted by the plasma. The omA programming enables to choose the width of the spectral range within a band of $3 \mathrm{~A}$ fixed by the size of the streak-camera photocathode. The spectral resolution is defined by the OMA track width. A maximum of 30 tracks can be practically used and the resolution can go up to $0.1 \mathrm{~A}$. The data are recorded by a computer which produces curves of soft $\mathrm{X}$-ray intensity time-variation at each wavelength.

Now the characteristic feature of an amplified radiation intensity is its relation with the length covered in the emitting medium. G being the galn coefficient, L, the length, $S$ the source function, the intensity reads :

$$
I=S\left(e^{G L}-1\right)
$$

whereas at wavelengths where the medium is absorbing, with a absorption coefficient $\alpha$, one has :

$$
I=S^{\prime}\left(1-e^{-\alpha L}\right)
$$

both expressions reducing each other with the substitution :

$$
G=-\alpha ; S=-S^{\prime}
$$

$G$ is proportional to the population inversion density as well as to the transition oscillator strength.

From (1), (2) and (3) it results that gain and absorption coefficients can be deduced from intensity measurements for various plasma lengths, the source function $S$ being left unchanged. In particular, if $L$ and 1 are the lengths of two plasmas columns of same density and temperature, $I_{1}$ and $I_{1}$ being the corresponding intensities at a given frequency, the absorption coefficient for this frequency is obtained by solving the equation :

$$
\left(1-e^{-\alpha L}\right) /\left(1-e^{-\alpha 1}\right)=I_{L} / I_{1}
$$

Basically, two laser shots used with two different column lengths are enough to achieve one gain measurement. In fact, the small reproducibility of laser operating 


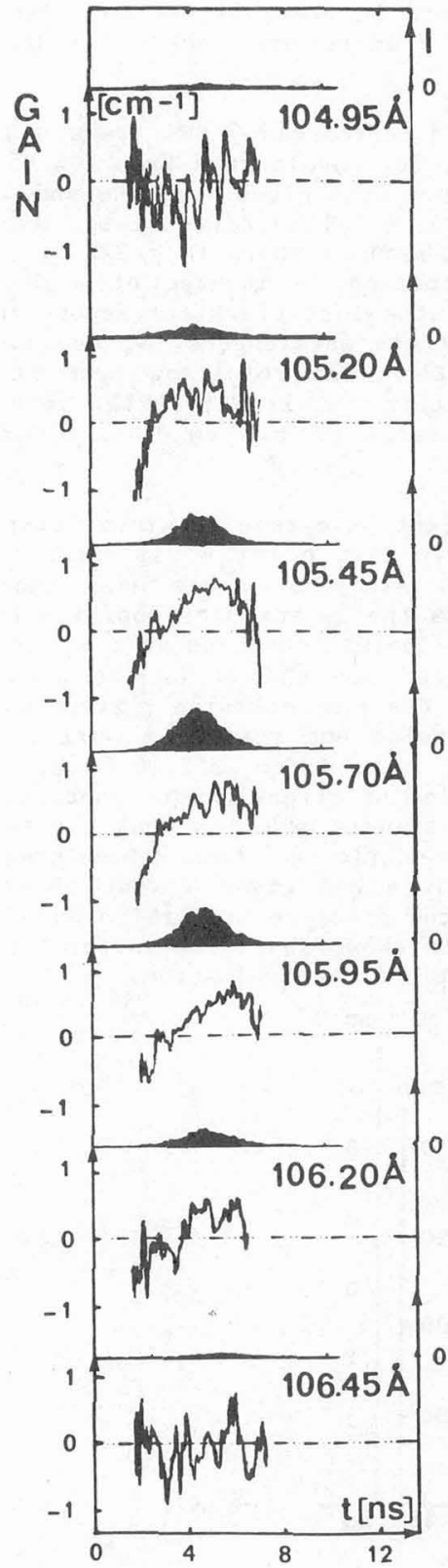

Fig. 5 - Gain as a function of time for the $3 d-5 f$ transition of $\mathrm{Al}^{10^{+}}$measured for a $2 \mathrm{~cm}$ long plasma column at a distance $X=0.6 \mathrm{~mm}$ from the target. The black areas represent the line intensity at various wavelengths close each other (OMA tracks). The top of the line is at 105.7 A. The laser-pulse half-maximum duration is 2.5 ns. The laser-flux inear density is about $22 \mathrm{GW} / \mathrm{cm}$.
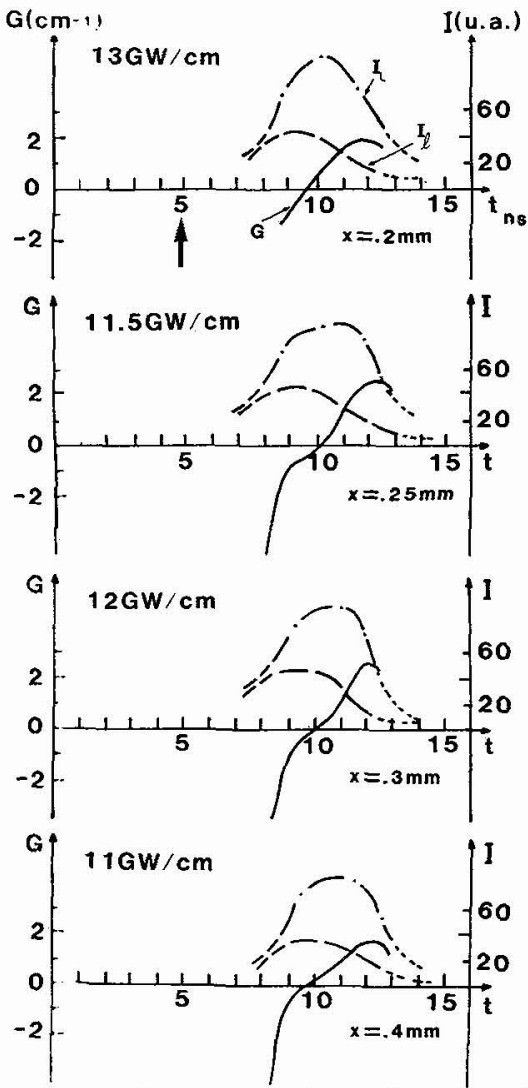

Fig. 6 - Time-variation of gain $G$ at $\lambda=105.7$ A in aluminum plasma at various distances $X$ from the solid target (solid curves); the arrow points at the top of the 3.7 ns laser-pulse; $I_{\text {and }} I_{1}$ (brocken curves) are respectively the intensities of the long ( $L=0.8 \mathrm{~cm})$ and the short $(1=0.37 \mathrm{~cm})$ plasma columns, measured from smoothed densitometry of streak camera photographies. $G$ is deduced from the ratio $I_{L} / I_{1}$ (see text). 
conditions makes serviceable to record a set of data in order either to select two matched shots or to average up intensities coming from several shots. The accuracy of the method is discussed elsewhere $/ 1,7,8 /$.

An example of the results is given in fig. 5 which reproduces 7 omA traks sampling the time-dependence of the $3 \mathrm{~d}-5 f$ line of Al $10+$, for wavelengths from $104.95 \mathrm{~A}$ to $106.45 \mathrm{~A}$ (darkened areas). The curve below each black area gives $\mathrm{G}$ at the same wavelength. The plasma lengths are $L=2 \mathrm{~cm}$ and $1=0.9 \mathrm{~cm}$. Intensities averaged respectively over 3 shots $(E=220 \mathrm{~J}, 215 \mathrm{~J}, 194 \mathrm{~J}$ ) and 2 shots $(E=222 \mathrm{~J}, 194 \mathrm{~J})$ are used in equation (4). The observed plasma section is located at a distance $x=0.6 \mathrm{~mm}$ from the target surface. The first and the last track correspond to the continuum spectrum on each side of the line. At these wavelengths, $G$, as given by (4), has a negative mean value with strong oscillations resulting from the low signal to noise ratio. All other wavelengths, within the line profile, reveal an actual gain having approximately the same peak value of $0.8 \mathrm{~cm}^{-1}$ at $105.45 \mathrm{~A}$, $105.7 \mathrm{~A}$ and $105.95 \mathrm{~A}$.

Up to now, the largest values of the gain coefficient have been obtained for plasma columns of length about $1 \mathrm{~cm}$. Results are shown in fig. 6 for 4 distances to the target surface, $X=0.2 \mathrm{~mm}, 0.25 \mathrm{~mm}, 0.3 \mathrm{~mm}, 0.4 \mathrm{~mm}$. All the curves have the same arbitrary time origin. The arrow at 5 ns indicates the approximate position of the top of the laser pulse deduced from the continuous thermal spectrum at $X=0 \mathrm{~mm}$. The pulse duration at half-maximum was $3.7 \mathrm{~ns}$. One can see that : i) the plasma is sytematically opaque during the first half-part of the line emission; ii) a gain is starting about 5 ns after the top of the laser pulse and reaches a maximum 2 ns later; iii) the peak value of the gain coefficient is as large as $2 \mathrm{~cm}^{-1}-2.5 \mathrm{~cm}^{-1}$. In the case of this experiment, where densitometries of streak-camera photographies were used instead of OMA tracks, the tails of the signals were too weak for the end of the gain pulse to be located. It must be mentionned that time-integrated measurement performed exactly in the same conditions has given a flat absorption spectrum in the region of the line, just like if the discrete transition had a zero contribution to a small absorption background. This shows that time-integration may result in concealing the gain occuring during the plasma recombination.

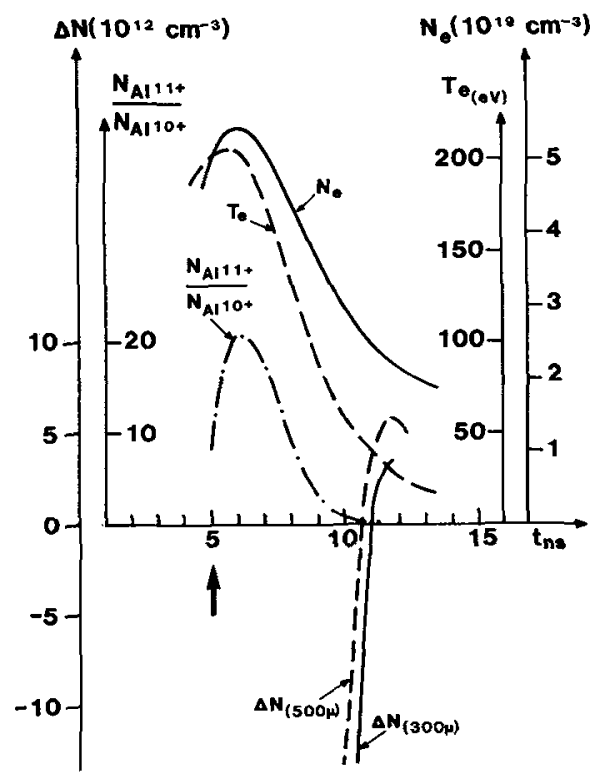

Fig. 7 - Calculated variation of plasma parameters for plasma production modelled on experimental conditions; the arrow points again at the top of the theoretical 3.7 ns-wide laser-pulse; $\Delta \mathrm{N}$ is the calculated population inversion density between the $3 \mathrm{~d}$ and $5 \mathrm{f}$ levels of $\mathrm{Al}^{+}$ions; the time scale is the same as in fig. 6. 
In order to account detailedly for the observation of a gain peak in the plasma about $7 \mathrm{~ns}$ after the top of the laser pulse, we performed the calculation of Al lof excited level populations in connection with plasma hydrodynamical simulation. This last is carried out in cylindrical geometry with using a one-dimensional numerical code /10/. The time-variation of electronic density, $N_{\text {, }}$, and temperature, $T$, of the plasma at distance $X=300 \mu$ from target surface, for a laser-pulse very' similar to the experimental ones, is displayed in fig. 7 , where the arrow points out again the top of the laser pulse. The figure shows the electron temperature to drop down rapidly during the plasma stage of interest. This fast decay of $T_{\text {f }}$ is one of the requirements of the recombination scheme of population inversion.

The Al ${ }^{10+}$ level populations have been calculated by building a radiativo-collisional model which includes the 48 levels of n-quantum number from 2 to 7 . Details on this model are to be found elsewhere/1,6,7/ as well as a discussion of the main features of stationary or time-dependent solutions of population equations. It is shown that these features, especially the occurence of population inversion between levels 3 and 5, are closely related to the abundance ratio of Helium-1ike to Lithium-1ike ions at each plasma temperature. That is why this ratio, calculated from the hydrodynamical code, is represented as a function of time in fig. 7 .

If, during all the recombination time, the $\mathrm{Al}{ }^{11+} / \mathrm{Al}{ }^{10+}$ ratio would get the equilibrium value fixed by plasma density and temperature, no population inversion could occur. What is shown by joining both abundance ratio and Al 10+ level population calculations is the electron temperature to decrease too fast for the equilibrium to be achieved all the time. As a consequence of this recombination delay, population inversions appear between some levels of Lithium-like ions. Fig. 7 shows the inversion density $\Delta \mathrm{N}=\mathrm{N}_{2} / \mathrm{g}_{2}-\mathrm{N}_{1} / \mathrm{g}_{1}$ calculated as a function of time, at two distances from the target, for the ${ }^{1} 3 \mathrm{~d}^{1}$ and $5 f$ levels, i.e. the two levels involved in the experimental results of fig. 7. The $A 1^{1} 0^{f}$ density during the same time is comprised between $10^{18 \mathrm{~cm}^{-3}}$ and $5 \times 10^{17} \mathrm{~cm}^{-3}$.

The absolute value of $\Delta_{N}$ is very sensitive to $N_{\text {f }}$ and $T_{e}$ at each step of the calculation. Hence a moderate underestimation of the cooling rate entails a much stronger underestimation of the inversion density. Thus the fact that the hydrodynamical simulation is one-dimensional and, on the other hand, does'nt take into account accurately the plasma radiative losses, reduces the precision of the full calculation especially as regards the absolute population values. Neglecting the levels of quantum number larger than 7 is a supplementary underestimation factor in the calculation of $N$ since it reduces the effective recombination rate to the $5 f$ levels during the plasma cooling. This makes difficult to get a significant value of the maximum gain from the model at the present time. However the conspicuous result of the completely ab initio calculation represented in $f i g$. 7 is the prediction of the $3 \mathrm{~d}-5 \mathrm{f}$ inversion starting almost exactly at the same time as the observed gain. This agreement between calculation and experiments is the demonstration of the relevance of the recombination scheme for generating soft $X-r a y$ amplification in Lithium-like ions.

A important question is brought up from the comparison of the results of fig. 5 and 6. Although the experimental conditions are not very different as regards the laser shot parameters and the distance of the plasma section to the target surface, the gain coefficient is found to be significantly smaller when measured for a $2 \mathrm{~cm} 10 \mathrm{ng}$ plasma than for a $0.8 \mathrm{~cm}$ long one. We made a similar observation in a previous experiment using time-integrated measurements/11/. In order to understand this discrepancy, we assumed that the radiative transfer, which is not included in the rate equations, has a part in the level populations. More specifically, the radiation trapping in the $2 p-3 d$ transition (see fig. 1) is likely increasing with the plasma length. So could it reduce the effective decay velocity of the $3 d$ level, leading at the same time to a smaller $3 d$ - $5 f$ inversion density.

The result shown in fig. 8 is an additional clue of the actuality of this effect. In one and the same set of laser shots, keeping a constant distance $X=0.2 \mathrm{~mm}$ to the target surface (instead of $X=0.6 \mathrm{~mm}$ in the example of $\mathrm{fig} .5$ ), we recorded the 
data corresponding to 3 plasma lengths, $0.57 \mathrm{~cm}, 1.2 \mathrm{~cm}$ and $2 \mathrm{~cm}$. Due to a plasma density larger than in the case of fig. 5, the effect of radiation trapping is expected to be more effective. As a matter of fact, for the shortest length pair, we found a gain coefficient going through a maximum about $1.5 \mathrm{~cm}^{-1}$, whereas the same while in plasma recombination ( $4 \mathrm{~ns}-6 \mathrm{~ns}$, in fig. 8) brings only on a drop of the opacity in the case of the longest pair. This result is so much the more noticeable that the laser flux was larger in the last case (20 GW/cm versus $12 \mathrm{GW} / \mathrm{cm}$ ), what would increase the population inversion density if no secondary effect occured.

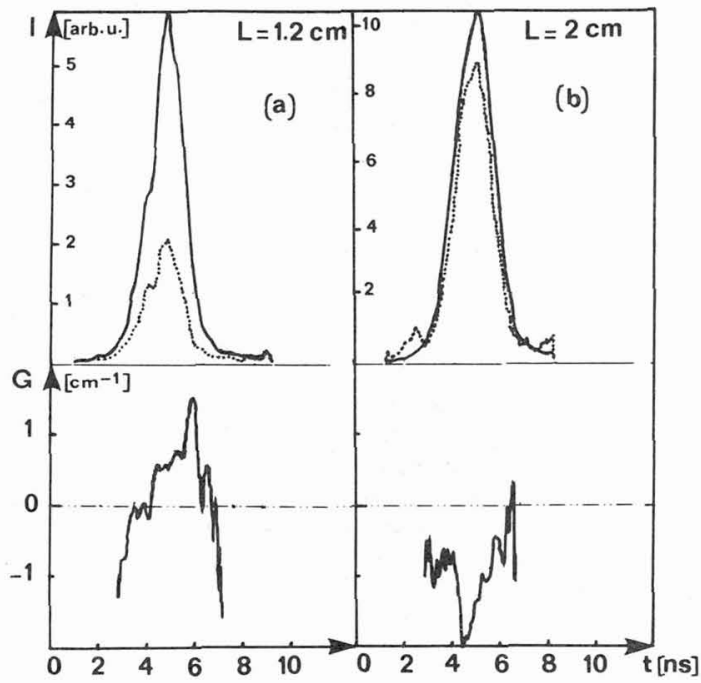

Fig. 8 - Intensity of the 105.7 A line for two pairs of plasma lengths at short distance from the target $(X=0.2 \mathrm{~mm})$. a) dotted line: $1=0.57 \mathrm{~cm}$, solid line: $\mathrm{L}=1.2 \mathrm{~cm} ; \mathrm{b})$ dotted line: $1=1.2 \mathrm{~cm}$, solid line: $\mathrm{L}=2 \mathrm{~cm}$. The suppression of gain in case b) is likely a consequence of the increasing of radiation trapping in the $2 p-3 d$ transition.

\section{III - RESEARCH PROGRAM}

At the present stage of the work, we obtain an emission at 105.7 A with a gain-1ength product G.L $=2$ - 2.5. Our program aims to increase this value by a factor 5 - 10 and to investigate other transitions liable to amplify radiation at new wavelengths. New Li-like ions, like s $13+$ are considered for future experiments/5/.

This effort makes necessary to carry out a large volume of computational modelling/4/. This concerns first the choice of laser shot parameters providing the highest possible gain coefficient. Examples of the role of pulse-duration and laser-flux are given in fig. 9 and $f i g .10$ where the $3 d-5 f$ inversion density is represented as a function of the distance to the target, at various instants. For the 2 ns pulse (fig. 9) we see that increasing laser-flux by a factor almost 2 has practically no effect on the maximum inversion density but offers a larger room to inversions in front of the target. Of course too small flux could not give any inversion and fig. 10 shows clearly that $4 \mathrm{GW} / \mathrm{cm}$ is hardly above the threshold of gain production in the case of 600 ps laser-pulse. In comparing fig. 9 and 10 , we see also that, at constant laser-flux, to go from 2 ns to 600 ps must increase the inversion density by a factor 5. However we have no experimental confirmation of this prediction to date.

Another important aspect of modelling will be to specify new target designs, capable to reduce the $2 p-3 d$ radiation trapping, the limiting role of which has been 

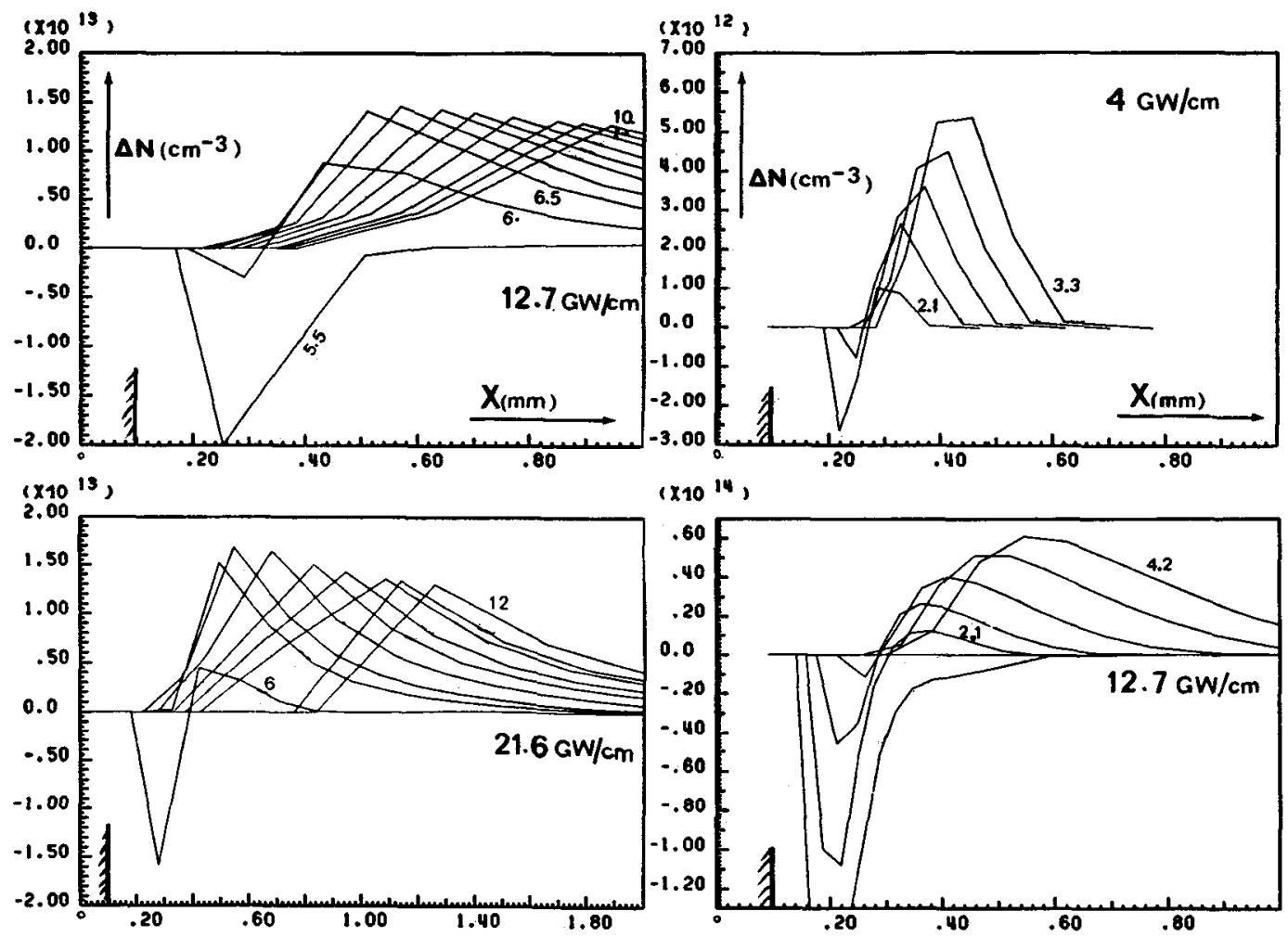

$\left(210^{14}\right)$
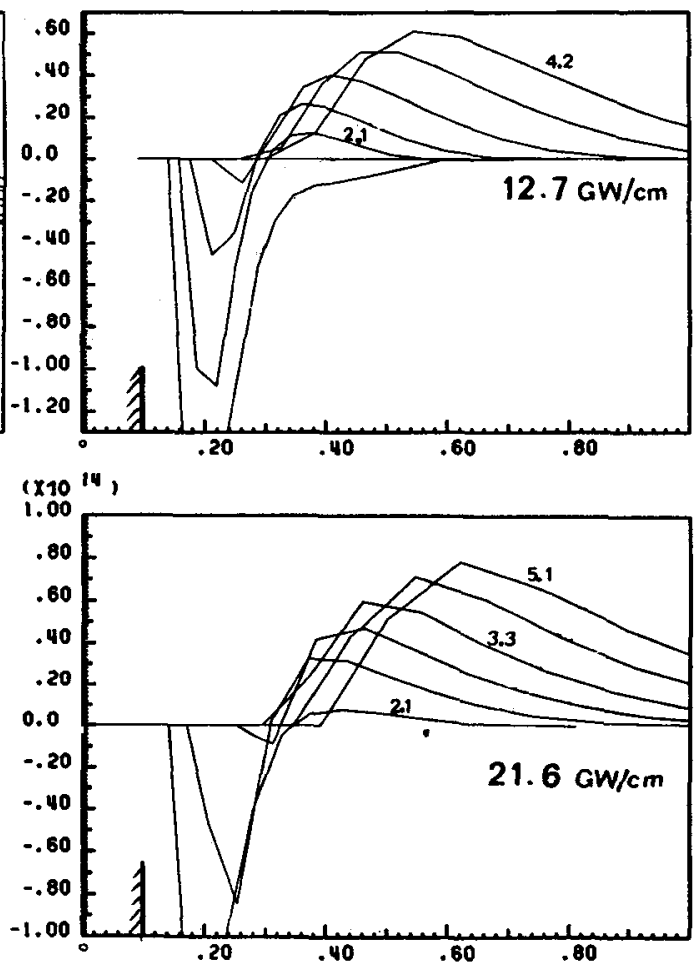

Fig. 9 - Inversion density calculated for the $3 d$ - $5 f$ transition of Li-like aluminum versus the distance to the target, at intervals of $0.5 \mathrm{~ns}$. The half-maximum pulse-duration is 2 ns and the time origin is such as the top of laser-pulse occurs at 2 ns. The wavelength of the laser is 1.06 . Hachure lines point out the initial position of the target surface.

Fig. 10 - Same as fig. 9 but for laser-pulse duration 600 ps. From top to bottom, time intervals between the curves are respectively 300 ps, 525 ps and 600 ps.

pointed out above regarding plasma columns longer than $1 \mathrm{~cm}$. Massive targets, used up to now owing to their technical convenience for great laser-shot repetition, produce a large amount of opaque plasma which prevents photon escape perpendiculary to the plasma column axis. Fibers, thin foils and coated lines will be investigated. 
A preliminary attempt to use a multilayer mirror for increasing the gain has been made. A plane mirror gave no clear evidence of the wanted effect but it is easy to see that, as long as the soft X-ray bean is not parallel, the efficiency of the plane mirror is very weak if its distance to the end of the plasma column is not itself very small. New experiments, with a concave multilayer mixror, have to be made.

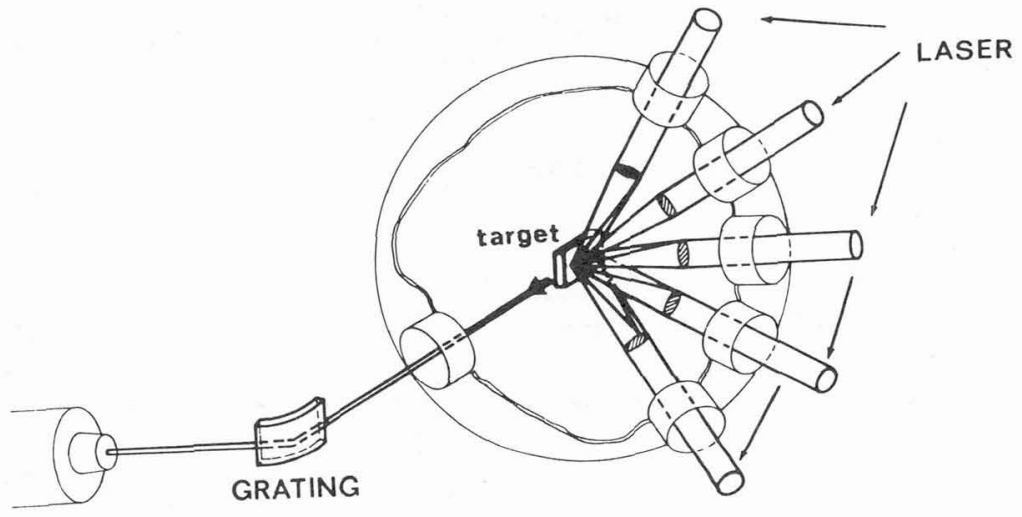

Fig. 11 - Sketch of the future X-ray laser experiment at Greco "Interaction Laser-Matiè re".

In order to increase the length of the plasma-column, with the same magnitude of laser-flux density, we need a laser energy larger than it was in the previous experiments. In view of inertial confinement studies, the laser facilities of Greco "Interaction Laser-Matière" have been recently extended and six beams are now available instead of the two we could use till now/12/. Our project consists in using five of the beams, in the way shown in fig. 11. Whith these facilities, a new focusing optics will allow to prepare $6 \mathrm{~cm}$ long plasmas for high gain experiments.

The authors aknowledge the financial support of D.R.E.T under contract $\mathrm{N}^{\circ} 79-387$.

\section{REFERENCES :}

/1/ G. Jamelot, A. Klisnick, A. Carillon, H. Guennou, A. Sureau, P. Jaeglé, J. Phys. B, 18 (1985) 4647,

/2/ P. Jaeglé, A. Carillon, A. KLisnick, G. Jamelot, H. Guennou, A. Sureau, Europhys. Lett., 1 (1986) 555

/3/ J.C. Gauthier, J.P. Geindre, P. Monier, in the same volume.

/4/ A. Klisnick, H. Guennou, J. Virmont, in the same volume.

/5/ H. Guennou, A. Sureau, C. Möller, in the same volume.

/6/ H. Guennou, Thèse de Doctorat d'Etat, Université Paris-Sud, $\mathrm{N}^{\circ}$ 2705, (1983).

/7/ P. Jaeglé, G. Jamelot, A. Carillon, A. Klisnick, A. Sureau, H. Guennou, in Laser Techniques in the Extreme Ultraviolet, ed. by S.E. Harris and T. B. Lucatorto, (American Institute of Physics, New York, N.Y., 1984), P. 468.

/8/ A. Klisnick, P. Jaeglé, G. Jamelot, A. Carillon, in Spectral Line Shapes, ed. by F. Rostas, vol. 3 (Walter de Gruyter, 1985), p. 157.

/9/ A. Carillon, P. Jaeglé, G. Jamelot, C1. Wehenkel, in Laser Interaction and Related Plasma phenomena, vol, 5, ed by H.J. Schwarz, H. Hora, M. Lubin and B. Yaakobi, Plenum Publishing Corporation, 1981, p. 277.

$/ 10 /$ J. Cl. Gauthier, J.P. Geindre, N. Grandjouan, J. Virmont ,J. Phys. D, 16 (1983) 321.

/11/ G. Jamelot, P. Jaeglé, A. Carillon, A. Klisnick, M. Lamoureux, Annual Report of Greco "Interaction Laser-Matière", Ecole Polytechnique, Palaiseau (1982) p. 142.

$112 /$ E. Fabre, Invited Conference at the $17^{\circ}$ European Conference on LaserInteraction with Matter, Rome, November 18-22, 1985, unpublished; Annual Report of Greco "Interaction Laser-Matière" (1985), in press. 